\title{
SISTEM PENDUKUNG KEPUTUSAN SELEKSI PENERIMA BEASISWA DENGAN METODE WEIGHTED PRODUCT PADA SMP NEGERI 1 PARUNG BERBASIS WEB
}

\author{
PETRICIA OKTAVIA \\ Staf Pengajar Fakultas Teknik Prodi Teknik Informatika \\ Universitas Pamulang, Tangerang Selatan, Banten \\ e-mail : dosen00638@unpam.ac.id
}

\begin{abstract}
ABSTRAK
Sistem pendukung keputusan sebagai sebuah sistem berbasis komputer yang membantu dalam proses pengambilan keputusan. Sistem pendukung keputusan sebagai sistem informasi berbasis komputer yang adaptif, interaktif, flaksibel, yang secara kusus dikembangkan untuk mendukung solusi dari permasalahan manajemen yang tidak terstruktur untuk meningkatkan kualitas pengambilan keputusan. Sistem pendukung ini membantu dalam proses pengambilan keputusan dalam seleksi penerima beasiswa di SMP Negeri 1 Parung. Pada sistem pendukung keputusan ini diperlukan kriteriakriteria untuk menentukan siapa yang akan dipilih untuk menerima beasiswa. Dalam pembangunan sistem pendukung keputusan ini penulis menggunakan metode Weighted Product sebagai metode pengambilan keputusan. Metode Weighted Product ini dipilih karena merupakan penjumlahan terbobot untuk mencari penjumlahan terbobot dari rating kinerja pada setiap alternatif pada semua atribut. Maka hasil keputusan pemilihan beasiswa yaitu pada alternatif ke 2 dari 5 alternatif dengan nilai 0.2104.
\end{abstract}

Kata Kunci : Sistem pendukung keputusan, Seleksi penerima beasiswa. Weighted Product.

\section{PENDAHULUAN}

Beasiswa dapat dikatakan sebagai pembiayaan yang tidak bersumber dari pendanaan sendiri atau orang tua, akan tetapi diberikan oleh pemerintah, perusahaan swasta, kedutaan, universitas serta lembaga pendidik atau peneliti, juga dapat dari kantor tempat bekerja yang karena prestasi seorang karyawan dapat diberikan kesempatan untuk meningkatkan kapasitas sumber daya manusianya melalui pendidikan (Gafur,2010). Biaya tersebut diberikan kepada yang berhak menerima, terutama berdasarkan klasifikasi, kualitas,dan kompetensi si penerima beasiswa.

Demikian halnya dengan SMP Negeri 1 Parung yang telah memiliki program pemberian beasiswa terhadap siswa. Oleh karena itu siswa harus diberikan kepada penerima yang layak dan pantas untuk mendapatkannya. Dalam menetukan penerima beasiswa telah menggunakan bantuan komputer , tetapi penggunanya belum optimal. Hal ini menyebabkan pengolalaan data beasiswa yang tidak efisien terutama dari segi waktu dan banyaknya perulangan proses yang sebenarnya dapat diefisienkan. Pengolalaan data beasiswa yang belum terakumulasi menggunakan database secara optimal juga menyebabkan kesulitan dalam pemprosesan data. Sehingga menyebabkan lamanya proses penentuan beasiswa. Olehkarena itu, perlu adanya suatu sistem yang mendukung proses penentuan penerima beasiswa, sehingga dapat mempersingkat waktu penyeleksian dan dapat meningkatkan kualitas keputusan dalam penentukan penerima beasiswa.

Penyelesaian masalah menggunakan FMADM seperti simple additive weighting (SAW), weighted product (WP), technique for order similarity to ideal solution(topsis)dan Analytic Hierarchy Process(AHP) banyak digunakan oleh peneliti.

Model yang digunakan dalam sistem aplikasi pendukung keputusan ini adalah Fuzzy Multiple Attribute Decision Making (FMADM) dengan metode weighted product. Metode weighted product ini di pilih karena metode tersebut menentukan nilai bobot untuk setiap atribut, kemudian dilanjutkan dengan proses pemeringkatan yang akan menyeleksi alternatif terbaik dari sejumlah alternatif, dalam hal ini alternatif yang dimaksud adalah siswa yang berhak menerima beasiswa berdasarkan kriteriakriteria yang di tentukan. 
Dengan metode pemeringkatan tersebut, diharapkan penilaian akan lebih tepat karena didasarkan pada nilai kriteria dan bobot yang sudah ditentukan sehingga akan mendapatkan hasil yang lebih akurat.

\subsection{Rumusan Masalah}

Berkaitan dengan pemaparan pada identifikasi masalah diatas, munculah pertanyaan dari peneliti. Adapun pertanyaan tersebut adalah : "Bagaimana menerapkan metode Weighted Product (WP) untuk sistem pendukung keputusan pemberian beasiswa agar lebih cepat dan tepat?"

\subsection{Tujuan Penelitian}

Adapun tujuan dalam penelitian ini yaitu sebagai berikut :

a. Merancang sistem pendukung keputusan agar dapat mengoptimalkannya penggunaan komputer dalam menentukan penerima beasiswa, sehingga menyebabkan pengelolaan data beasiswa menjadi tidak efisien.

b. Merancang sistem pendukung keputusan agar dapat membantu dalam pengelolaan data beasiswa yang belum terakumulasi menggunakan database secara optimal juga menyebabkan kesulitan dalam pemrosesan data, sehingga menyebabkan lamanya proses penentuan penerima beasiswa.

\section{METODE PENELITIAN}

Sistem Pendukung Keputusan (SPK) adalah suatu sistem informasi berbasis komputer mengkombinasikan model dan data untuk menyediakan dukungan kepada pengambil keputusan dalam memecahakan masalah semi terstruktur atau masalah ketergantungan yang melibatkan user secara mendalam(Dewantoro, 2013).

Sementara itu, perintis sitem pendukung keputusan yang lain dari MIT, yaitu Peter G.W. Keen yang bekerja sama dengan Scott Morton telah mendefinisikan tiga tujuan yang harus dicapai oleh sistem pendukung keputusan yaitu:

a. Sistem harus dapat membantu manajer dalam membuat keputusan guna memecah masalah semi tersetrukur. b. Sistem harus dapat mendukung manajer, bukan mencoba menggantikannya.

c. Sistem harus meningkatkan efektifitas mengambilan keputusan manajer.

Karakteristik dan kapabilitas kunci dari sistem sendukung seputusan adalah sebagai berikut(Minartiningtyas, 2013):

a. Menyediakan dukungan bagi pengambil keputusan utamanya pada situasi semi terstruktur dan tak terstruktur dengan memadukan pertimbangan manusia dan informasi terkomputerisasi.

b. Dukungan disediakan untuk pelbagai level manajerial yang berbeda, mulai dari pimpinan puncak sampai manajer lapangan.

c. Dukungan disediakan bagi individu dan juga bagi group. Pelbagai masalah organisasional melibatkan pengambilan keputusan dari orang dalam group. Untuk masalah yang strukturnya lebih sedikit seringkali hanya membutuhkan keterlibatan beberapa individu dari departemen dan level organisasi yang berbeda.

d. Menyediakan dukungan ke pelbagai keputusan yang berurutan atau saling berkaitan.

e. Mendukung pelbagai fase proses pengambilan keputusan: intelligence, design, choice dan implementation.

f. Mendukung pelbagai proses pengambilan keputusan dan style yang berbeda-beda; ada kesesuaian diantara SPK dan atribut pengambil keputusan individu (contohnya vocabulary dan style keputusan).

g. Bisa beradaptasi sepanjang masa. Pengambil keputusan harus reaktif, mampu mengatasi perubahan kondisi secepatnya dan beradaptasi untuk membuat DSS selalu bisa menangani perubahan ini.

h. Pengambil keputusan memiliki kontrol menyeluruh terhadap semua langkah proses pengambilan keputusan dalam menyelesaikan masalah. SPK secara khusus ditujukan untuk mendukung dan tak menggantikan pengambil keputusan. Pengambil keputusan dapat menindak lanjuti rekomendasi komputer sembarang waktu dalam proses dengan tambahan pendapat pribadi atau pun tidak. 
Dengan berbagai karakter khusus seperti dikemukakan di atas, sistem pendukung keputusan dapat memberikan berbagai manfaat atau keuntungan bagi pemakai (Subakti, 2003). Kemampuan dimaksud di antaranya meliputi:

a. Mampu mendukung pencarian solusi dari masalah yang kompleks.

b. Respon cepat pada situasi yang tak diharapkan dalam kondisi yang berubahubah.

c. Mampu untuk menerapkan pelbagai strategi yang berbeda pada konfigurasi berbeda secara cepat dan tepat.

d. Pandangan dan pembelajaran baru.

e. Memfasilitasi komunikasi.

f. Meningkatkan kontrol manajemen dan kinerja.

Sistem Pendukung Keputusan terdiri dari empat subsistem, yaitu:

a. Subsistem Manajemen Data

Subsistem Manajemen Data memasukkan satu database yang berisi data yang relevan untuk situasi dan kondisi. Dikelola oleh perangkat lunak yang disebut Sistem Manajemen Database (DBMS/Database Management System). Subsistem manajemen data bisa diinterkoneksikan dengan data warehouse perusahaan, suatu repository untuk data perusahaan yang relevan dengan pengambilan keputusan

b. Manajemen Model berupa sebuah paket perangkat lunak yang berisi model-model finansial, statistic, manajement science, atau model kuantitatif, yang menyediakan kemampuan analisa dan perangkat lunak manajemen yang sesuai.

c. Subsistem Antarmuka Pengguna (Dialog) Istilah antarmuka pengguna mencakup semua aspek komunikasi antara pengguna dan sistem. Cakupannya tidak hanya perangkat keras dan

d. Subsistem Manajemen Berbasis Pengetahuan (Knowledge Base)

Subsistem ini mendukung semua subsistem lain atau bertindak sebagai suatu komponen independen yang memberikan intelegensi untuk memperbesar pengetahuan si pengambil keputusan. Subsistem ini dapat diinterkoneksikan dengan repositori pengetahuan perusahaan organisasional

\subsection{Fuzzy Multiple Attribute Decision Making (FMADM)}

JURNAL INFORMATIKA UNIVERSITAS PAMULANG

Vol. 3, No. 2, Juni 2018
FuzzyMultiple Attribute Decision Making (FMADM) adalah suatu metode yang digunakan untuk mencari alternatif optimal dari sejumlah alternatif dengan kriteria tertentu. Inti dari FMADM adalah menentukan nilai bobot untuk setiap atribut, kemudian dilanjutkan dengan proses perankingan yang akan menyeleksi alternatif yang sudah diberikan. Pada dasarnya, ada 3 pendekatan untuk mencari nilai bobot atribut, yaitu pendekatan subyektif, pendekatan obyektif dan pendekatan integrasi antara subyektif dan obyektif. Masing masing pendekatan memiliki kelebihan dan kelemahan. Pada pendekatan subyektif, nilai bobot ditentukan berdasarkan subyektifitas dari para pengambil keputusan, sehingga beberapa faktor dalam proses perankingan alternatif bisa ditentukan secara bebas.

Sedangkan pada pendekatan obyektif, nilai bobot dihitung secara matematis sehingga mengabaikan subyektifitas dari pengambil keputusan (kusumadewi, 2007).

Ada beberapa metode yang dapat digunakan untuk menyelesaikan masalah FMADM, yaitu (Karmilasari, 2008):

a. $\quad$ Simple Additive Weighting Method (SAW)

b. Weighted Product (WP)

c. ELECTRE

d. Technique for Order Preference by Similarity to Ideal Solution (TOPSIS)

e. Analytic Hierarchy Process (AHP)

\subsection{Metode Weighted Product (WP)}

Dalam penentuan nilai kepentingan atau bobot pada aplikasi sistem penunjang keputusan sebagai alat bantu, pencarian nilai bobot atribut menggunakan penilaian secara subyektif yaitu dengan diberi peringkat 1 sampai 5 berdasarkan jenis dan beberapa kriteria yang telah dipilih sebelumnya.

Metode weighted product menggunakan perkalian untuk menghubungkan rating atribut, dimana rating setiap atribut harus dipangkatkan dulu dengan bobot yang bersangktutan. Proses ini sama halnya dengan proses normalisasi.

Preferensi untuk alternatif :

$\sum$

$$
\mathrm{V}_{\mathrm{i}}=\frac{\prod_{j=1}^{n} \mathrm{Xij}^{w j}}{\prod_{j=1}^{n}\left(\mathrm{Xj}^{*}\right)^{w j}}
$$

Dimana:

\author{
Vol. 3, No. 2, Juni 2018
}




Si = Vektor tiap alternatif
Xij = Nilai dari input kriteria ke-
wj = Bobot kriteria ke-
$=$ baris
$=$ kolom
n= Banyaknya kriteria
Perbaikan bobot akan dihitung dengan
S

Dimana :

wj $\quad=$ bobot ke- $\sum$

Preferensi relative dari setiap alternative diberikan sebagai :

atau

Dimana :

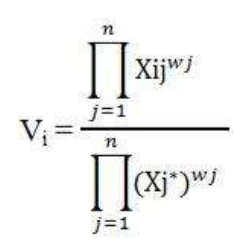

$\mathrm{S}_{\mathrm{i}} \quad=$ Vektor tiap alternatif

$\sum \mathrm{Si}=$ Jumlah dari $\mathrm{Si}$

$=$ Preferensi alternative dianalogikan sebagai vektor $\mathrm{V}$

$=$ Nilai kriteria

$=$ Bobot kriteria/subkriteria

$=$ baris $(1,2,3, \ldots, \mathrm{m})$

$=$ kolom

$\mathrm{n}=$ Banyaknya kriteria

$=$ Banyaknya kriteria yang telah dinilai pada vektor $\mathrm{S}$

\subsection{Pengembangan Sistem}

\subsubsection{Model Pengembangan Sistem Pendukung Keputusan}

Pengembangan suatu sistem pendukung keputusan terkait juga dengan struktur permasalahan tak terstruktur, semi terstruktur, ataupun terstruktur. Dibawah ini merupakan bagan fase-fase pengembangan sistem pendukung keputusan (Minartiningtyas, 2013):

a. $\quad$ Fase perencanaan (Planning)

Merumuskan kerangka dan ruang lingkup SPK, persyaratan unjuk kerja, memilih konsepkonsep dan menganalisis model pembuatan keputusan yang relevan dengan tujuan SPK.

b. Fase penelitian (Research)

Berhubungan dengan pencarian data serta sumber daya yang tersedia.

c. Fase analisis dan perancangan konsep (Analysis)

Penentuan teknik pendekatan yang akan dilakukan serta sumber daya yang dibutuhkan.

d. Fase perancangan (Design)

Melakukan perancangan ketiga subsistem utama SPK, subsistem database, model, Dialog.

e. Fase konstruksi (Construction)

Merupakan kelanjutan dari perancangan dimana ketiga subsistem yang telah dirancang digabungkan menjadi suatu SPK.

f. Fase implementasi (Implementation)

Menerapkan SPk yang dibangun, pada tahap ini dilakukan pengujian, evaluasi, penampilan, orientasi, pelatihan dan penyebaran.

g. Fase pemeliharaan (Maintenance)

Tahapan yang dilakukan terus menerus untuk mempertahankan keandalan sistem.

h. Fase adaptasi (Adaptation)

Melakukan pengulangan terhadap tahapan diatas sebagai tanggapan terhadap perubahan kebutuhan pemakai.

perangkat lunak, tapi juga faktor-faktor yang berkaitan dengan kemudahan pengunaan, kemampuan untuk dapat diakses, dan interaksi manusia-mesin. Beberapa ahli merasa bahwa antarmuka pengguna merupakan komponen yang paling penting karena merupaka sumber dari berbagai power,fleksibilitas, dan 
karakteristik easy-to-use. Ahli lainnya menyatakan bahwa antarmuka pengguna merupakan sistem dari sisi pengguna karena antarmuka adalah satu-satunya bagian dari sistem yang dilihat oleh pengguna.

\section{PEMBAHASAN} yaitu

Ada 6 siswa yang akan menjadi alternatif,

a. $\mathrm{A} 1=$ Siswa 1

b. $\quad \mathrm{A} 2=$ Siswa 2

c. $\mathrm{A} 3=$ Siswa 3

d. $\quad$ A4 $=$ Siswa 4

e. $\quad$ A5 $=$ Siswa 5

Ada 6 Kriteria yang dijadikan acuan dalam pengambilan keputusan, yaitu;

a. $\quad \mathrm{C} 1=$ Usia siswa(Tahun)

b. $\quad \mathrm{C} 2=$ Perilaku Siswa disekolah

c. $\quad \mathrm{C} 3=$ Jumlah saudara kandung (anak)

d. $\quad \mathrm{C} 4=$ Jumlah tanggungan orang tua(anak)

e. $\quad \mathrm{C} 5=$ Nilai rata-rata raport

f. $\quad$ C6 = Gaji Orang Tua (Rp/Bulan)

Selanjutnya pengambilan keputusan memberikan bobot preferensi untuk masingmasing kriteria adalah sebagai berikut : $\mathrm{W}=$ $(5,4,4,3,3,2)$

Berdasarkan data alternaatif diatas dapat dibentuk rating kecocokan dari setiap alternatif pada setiap kriteria, yang terlihat pada tabel berikut :

\begin{tabular}{|l|r|r|r|r|r|c|}
\hline \multirow{2}{*}{ Alternatif } & \multicolumn{6}{|c|}{ Kriteria } \\
\cline { 2 - 7 } & C1 & C2 & C3 & C4 & C5 & C6 \\
\hline A1 & 17 & 70 & 7 & 4 & 80 & 2.000 .000 \\
\hline A2 & 16 & 75 & 6 & 6 & 90 & 1.700 .000 \\
\hline A3 & 14 & 70 & 9 & 2 & 70 & 2.400 .000 \\
\hline A4 & 15 & 70 & 8 & 5 & 80 & 1.800 .000 \\
\hline A5 & 15 & 70 & 5 & 6 & 80 & 1.500 .000 \\
\hline
\end{tabular}

Tabel 3.1 Kriteria Penelitian

Kategori setiap kriteria merupakan kriteria keuntungan, sementara kriteria biaya tidak ada. Sebelumnya dilakukan perbaikan bobot terlebih dahulu sehingga $\sum \mathrm{W}=1$ maka didapat perhitungan sebagai berikut :

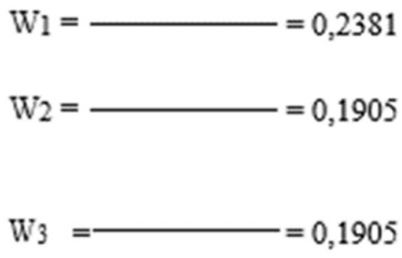

$\mathrm{W}_{4}=0,1429$

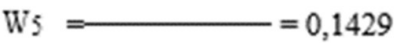

$W_{6}=-=0,0952$ berikut :

Kemudian vector S dapat dihitung sebagai $S_{1}=\left(17^{0,2381}\right)\left(70^{0,1905}\right)\left(7^{0,1905}\right)\left(4^{0,1429}\right)(80,0,429)(2,000.0000,0,0952)=57.9908$ $S_{2}=\left(16^{0,2381}\right)\left(77^{0,1905}\right)\left(6^{0,1905}\right)\left(6^{0,1429}\right)\left(90^{0,1429}\right)(1.700,0000,0,0952)=59,6743$ $S_{3}=\left(14^{0,2381}\right)\left(70^{0,1905}\right)\left(9^{0,1905}\right)\left(2^{0,1429}\right)\left(70^{0,4429}\right)(2,000.0000,0,052)=52.5199$ $S_{4}=\left(15^{0,2381}\right)\left(70^{0,1905}\right)\left(8^{0,1905}\right)\left(5^{0,1429}\right)\left(88^{0,1429}\right)(1.800 .0000,00952)=59,0132$ $S_{5}=\left(15^{0,2381}\right)\left(70^{0,1905}\right)\left(5^{0,1905}\right)\left(6^{0,1429}\right)\left(80^{0,4429}\right)(2,000,0000,0,0952)=54,4302$

Nilai vector $\mathrm{V}$ yang akan digunakan untuk perangkingan dapat di hitung sebagai berikut : 


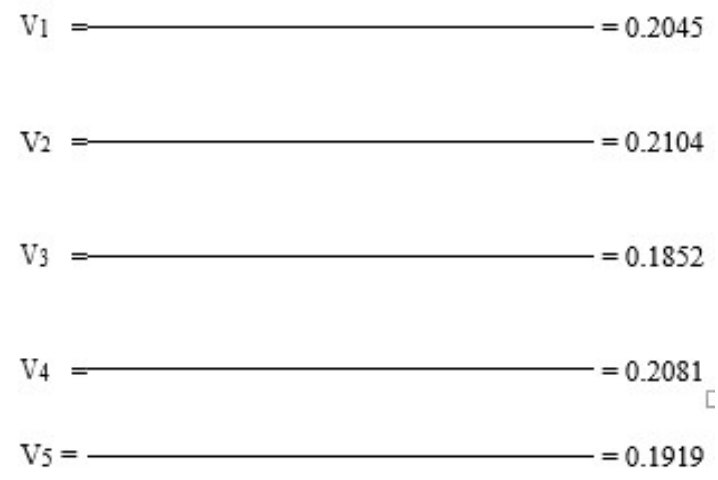

Dari hasil perengkingan diatas diperoleh $\mathrm{V}_{1}$ $=0.2045 ; \mathrm{V}_{2}=0,2094 ; \mathrm{V}_{3}=0.1852 ; \mathrm{V}_{4}=0.2081$; dan $\mathrm{V}_{5}=0.1919$. Nilai terbesar ada pada $\mathrm{V}_{4}$, sehingga alternatif $V_{2}$ adalah alternatif yang terpilih sebagai alternatif yang terbaik.

Use Case Diagram Pendaftaran Beasiswa Sistem Usulan

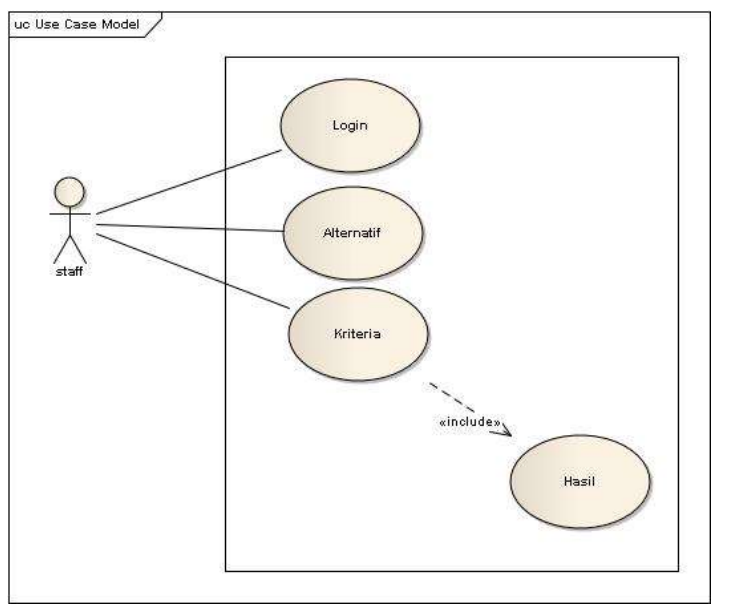

Gambar 3.1 Use Case Diagram Sistem Usulan

\section{HASIL PENELITIAN}

Berdasarkan hasil penelitian yang telah dilakukan, proses seleksi penerimaan beasiswa di SMP Negeri 1 Parung kurang efektif khususnya dari segi kualitas. Hal ini menyebabkan pengolahan data beasiswa yang tidak efisien terutama dari segi waktu dan banyaknya perulangan proses yang sebenarnya dapat di efisienkan. Setelah melakukan penelitian tersebut maka penulis mengusulkan suatu sistem pendukung keputusan yang dapat menjadi alat bantu dalam seleksi penerimaan beasiswa.

Dengan menerapkan metode Weighted Product (wp) dalam menentukan penerimaan beasiswa, karena proses pemeringkatan yang akan menyeleksi alternatif tersebut dari sejumlah alternatif, pada nilai kriteria dan bobot yang sudah ditentukan sehingga akan mendapatkan hasil yang akurat. Jadi siswa alternatif yang terpilih dengan nilai terbesar

Berdasarkan penelitian tersebut, maka penulis menyimpulkan bahwa sistem pendukung keputusan dengan menggunakan metode weighted product (wp), dapat digunakan dalam seleksi penerima beasiswa dan hasil yang diperoleh lebih akurat dibandingkan dengan proses seleksi yang dilakukan sebelumnya

\section{KESIMPULAN}

Berdasarkan pembahasan dan

evaluasi dari bab sebelumnya, maka dapat kesimpulan sebagai berikut :

a. $\quad$ Metode Weighted Product dapat diterapkan pada sistem pemberian beasiswa.

b. Dengan penerapan sistem ini penilaian pemberian beasiswa bisa dilakukan dengan lebih cepat dan dan tepat, dimana hasil keputusan pemilihan beasiswa yaitu pada alternatif ke 2 dari 5 alternatif dengan nilai 0.2104

\section{SARAN}

Berikut adalah beberapa saran untuk pengembangan lebih lanjut terhadap penelitian ini:

Dapat ditambahkan data lain yang mendukung penyeleksian beasiswa misalnya penambahan criteria

a. Sistem pemberian beasiswa ini masih dapat dikembangkan dengan menambahkan metode sistem pendukung keputusan yang lain seperti: Ahp, Topsis dan Saw.

b. Dengan adanya penelitian ini yang berbasis web, diharapkan dapat mengembangkan aplikasi berbasis deskop atau mobile.

\section{DAFTAR PUSTAKA}

1. Dewantoro, A. (2013). Sistem Pendukung Keputusan Menentukan Guru Teladan Di SMPN 24 SEMARANG Dengan Menggunakan Metode Simple Additive Weighting.

2. Fatta. (2007). Analisa Dan Perancangan Sistem Informasi .Yogyakarta: Andi. Fery Romidhoni Eprilianto, Tri Sagirani, Tan Amelia.(2011). Sistem pendukung 
3. Keputusan penerimaan beasiswa menggunakan metode saw di universitas panca marga probolinggo.

4. Gafur, A .(2008). Cara Mudah Mendapatkan Beasiswa. Jakarta: Elex Media Komputindo.

5. Gerdon.(2011). Sistem Pendukung Keputusan Untuk Menentukan Penerimaan Beasiswa Bagi Mahasiswa Di STMIK AMIKOM Yogyakarta.

6. Hartati, S. (2010). Analisis Sistem Informasi.

7. Huda, Miftakhul. (2010). Membuat Aplikasi Database Dengan Java, MySQL, dan NetBeans, Jakarta: Elex Media Komputindo. Karmilasari. (2008). Logika Fuzzy. Yogyakarta: Graha Ilmu.

8. Kusumadewi,S. (2007). Fuzzy MultiAttribut Decision Making (Fuzzy MADM). Yogyakarta: Graha Ilmu.

9. Kuswayanto, Lia. (2006). Mahir dan Trampil Berkomputer. Jakarta:Grafindo media Pratama.

10. Miko Krisiyanto Purba.(2012) sistem pendukung keputusan untuk menentukan penerimaan beasiswa bank bri mengunakan fmadm di universitas gunadarma. .
11. Minartiningtyas, B. A. (2013). Pengembangan Sistem Pendukung Keputusan. Musyawarah, Rina.(2005). Membangun aplikasi Database Berbasis Web untuk Pemula. Jakarta: Elex Media Komputindo.

12. Oktavian, Puji, Diar.(2010).Menjadi Programmer Jempolan Menggunakan PHP. Yogyakarta:Mediakom.

13. Subakti, I. (2003). Sistem Pendukung Keputusan. Yogyakarta: Graha Ilmu.

14. Sya'ban, Wahyu.(2010). Build Your Blogger Xml Template. Yogyakarta:Penerbit Adi Yogyakarta.

15. Wicaksono, Yogi.(2008). Membangun Bisnis Online Dengan Mambo. Jakarta : Elex Media Komputindo.

16. Widianto, E. D. (2012). Pemodelan Sistem Dengan UML. Yogyakarta: Graha Ilmu.

17. Yuhefizar.(2008). 10 jam Menguasi Internet, Teknologi Dan Aplikasi. Jakarta: Elex Media Komputindo 